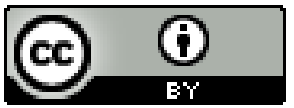

\title{
PRECISAMOS FALAR SOBRE HISTÓRIA E CULTURA AFRO- BRASILEIRA: UM OLHAR CRÍTICO SOBRE O LIVRO DIDÁTICO
}

\author{
José Luiz Xavier Filhol \\ Universidade de Pernambuco, Garanhuns, PE, Brasil.
}

Resumo: A pesquisa traz como objetivo analisar as possibilidades do professor em sala de aula para o entendimento e aplicação da Lei n. 10.639/2003 e a história e a cultura afro-brasileira, de modo a articular com o Livro Didático a expressar resultados que se processam com turmas de Ensino Fundamental dos Anos Finais. Propõe também abordar a cultura, e nesse contexto, as religiões de matriz africana, na percepção de significados dessa matriz na construção do ser brasileiro, em reflexão que se volte a formação dos estudantes nesse nível de ensino. Trata-se de uma pesquisa documental, recorrendo ao método observacional que traz como estudo de caso, focado no conteúdo programático a seguir de uma sequência de livro didático, que foram articuladas com as observações de professores.

Palavras-chave: Ensino de História; Religiões de Matrizes Africanas; Educação.

\section{WE NEED TO TALK ABOUT AFRO-BRAZILIAN HISTORY AND CULTURE: A CRITICAL LOOK AT THE TEXTBOOK}

\begin{abstract}
The research aims to analyze the possibilities of the teacher in the classroom for the understanding and application of Law no. 10,639 / 2003 and Afro-Brazilian history and culture, in order to articulate with the Didactic Book to express results that are processed with Elementary School classes of the Final Years. It also proposes to approach culture, and in this context, religions of African origin, in the perception of meanings of this matrix in the construction of the Brazilian being, in a reflection that turns the training of students at this level of education. It is a documentary research, using the observational method that brings as a case study, focused on the programmatic content following a textbook sequence, which were articulated with the observations of teachers.
\end{abstract}

Keywords: Teaching History; Religions of African Matrix; Education.

\footnotetext{
${ }^{1}$ Graduado em História (UPE), graduando em Sociologia (UNIFAVENI), especialista em Ensino de História (UNIFAVENI), e em História e Cultura Afro-Brasileira (IPEMIG), mestrando em Culturas Africanas, da Diáspora, e dos Povos Indígenas (UPE), professor de História do quadro efetivo da rede municipal de ensino do município da Lagoa dos Gatos - PE, ID Lattes: http://lattes.cnpq.br/4762429040202808 ; E-mail: jlxfilho@hotmail.com ; ORCID: https://orcid.org/0000$\underline{0001-9088-8610}$
} 


\section{NECESITAMOS HABLAR SOBRE LA HISTORIA Y LA CULTURA AFROBRASILEÑA: UNA MIRADA CRÍTICA AL LIBRO DE TEXTO}

Resumen: La investigación tiene como objetivo analizar las posibilidades del docente en el aula para la comprensión y aplicación de la Ley núm. 10.639 / 2003 e historia y cultura afrobrasileña, con el fin de articular con el Libro Didáctico para expresar resultados que se procesan con las clases de Educación Primaria de los Últimos Años. También propone acercar la cultura, y en este contexto, las religiones de origen africano, en la percepción de significados de esta matriz en la construcción del ser brasileño, en la reflexión que gira la formación de los estudiantes de este nivel educativo. Se trata de una investigación documental, utilizando el método observacional que trae como caso de estudio, enfocado en el contenido programático siguiendo una secuencia de libro de texto, los cuales fueron articulados con las observaciones de los docentes.

Palabras-clave: Enseñanza de la Historia; Religiones de Origen Africanos; Educación.

\section{NOUS DEVONS PARLER DE L'HISTOIRE ET DE LA CULTURE AFRO- BRÉSILIENNES: UN REGARD CRITIQUE SUR LE MANUEL}

Résumé: La recherche vise à analyser les possibilités de l'enseignant en classe pour la compréhension et l'application de la loi no. 10 639/2003 et l'histoire et la culture afrobrésiliennes, afin de s'articuler avec le livre didactique pour exprimer les résultats qui sont traités avec les classes de l'école élémentaire des dernières années. Il propose également d'aborder la culture, et dans ce contexte, les religions d'origine africaine, dans la perception des significations de cette matrice dans la construction de l'être brésilien, dans une réflexion qui transforme la formation des étudiants à ce niveau d'éducation. Il s'agit d'une recherche documentaire, utilisant la méthode d'observation qui apporte comme étude de cas, axée sur le contenu programmatique suivant une séquence de manuels, qui ont été articulées avec les observations des enseignants.

Mots-clés: Enseignement de L'Histoire; Religions Africaines; Éducation.

\section{INTRODUÇÃO}

Os currículos escolares, tem ainda insistido trabalhar a História tradicional do Ocidente, limitados por uma visão eurocentrista, e quase sempre trata como não relevante a história de outras regiões do mundo a exemplo da África. Esse olhar, que tem subordinado e diminuído a importância de outros povos apresenta a Europa como eixo do movimento evolutivo, impulsionado desde a Antiguidade, época em que a região mediterrânea era definida como o centro do mundo.

A África desde então, passou a ser vista como distante, como a região dos "homens de faces queimadas" (DEL PRIORE; VENÂNCIO, 2004, p. 56). Daquele 
período até o final da Idade Média, especialmente com a religiosidade cristã medieval, ganhou impulso a associação da cor negra ao pecado e ao demônio, firmando a visão preconceituosa em relação aos povos africanos. Para confirmar essa "inferiorização" da África, apontada como a região do mal, havia ainda uma passagem bíblica do Gênesis, a qual os referidos autores fazem menção:

Cã, segundo filho de Noé, exibiu-se diante de seus irmãos, gabando-se de ter visto o sexo de seu pai, quando esse se encontrava bêbado. Para castigá-lo, o patriarca amaldiçoou Canaã, filho de Cã; ele e sua descendência se tornariam servidores de seus irmãos e sua descendência. Eles migraram para o sul e para a cidade das sexualidades malditas: Sodoma. Depois atingiram Gomorra. Lendas contam que os filhos dos filhos dos amaldiçoados foram viver em terras iluminadas por um sol que os queimava, tornando-os negros. (DEL PRIORE \& VENANCIO,2004, p. 59).

A ideia de supremacia europeia trouxe ideologicamente a inferioridade de outras culturas, especialmente as africanas, consolidou-se durante a Idade Moderna, quando a Europa passou a centralizar o poder econômico, político e militar mundial. Por séculos prevaleceu a mentalidade de enquadrar os africanos num grau inferior da escala evolutiva, a mesma que classificava os vários povos em avançados e atrasados ou civilizados e primitivos, a exemplo do que foi disseminado sobre os africanos no imaginário de muitos brasileiros.

Comerciantes, conquistadores e teóricos ressaltavam uma suposta selvageria dos povos da África, característica quase sempre relacionada à natureza do continente, fundamentando assim a crença de que a identidade daqueles seria determinada meramente por traços físicos e biológicos, e não por sua história. Impunham essa versão forçada de que o homem africano era incapaz de produzir cultura e história, quadro que serviu aos escravagistas e também aos imperialistas do século XIX, os mesmos que utilizaram o discurso justificador de "civilizar" a África como afirmou Marc Ferro acerca do que era pensado pelos ingleses que somente haveria civilização pelos europeus. (FERRO, 2004).

Além dos indisfarçáveis interesses de conquista, exploração e dominação, esse discurso tradicional encobria as diversidades e características próprias dos povos africanos, decorrentes de milênios de sua história. Ao contrário do que prega essa versão estereotipada das populações e da cultura africana, o continente foi palco de uma ampla e complexa diversidade histórica, cultural e religiosa, que começa com os primórdios da humanidade. 
Os africanos que vieram para as Américas, em condição de escravizados, embora no mesmo período colonial tenha havido uma pequena imigração de africanos livres, provinham de diferentes povos que pertenciam a variadas culturas. As suas práticas religiosas eram, em alguns casos, assemelhadas e, em outros, bastante diferenciadas.

Um grande número de africanos e seus descendentes, porém, buscaram recriar as suas religiões de origem, formando grupos para a prática religiosa dos rituais e para a transmissão das tradições. Estes grupos se autodenominaram nações e os nomes adotados se referem às etnias, cujas culturas são predominantes entre eles.

O afro-brasileiro já nasce na perspectiva do colonizador, na medida em que suas relações sociais e culturais são modificadas historicamente pelos brancos, a segregação é real, acontece pelo racismo que faz parte do nosso cotidiano e se manifesta de todas as formas, é o racismo que molda os negros ao lugar de inferiorização e animalidade, às vezes ele é tão velado que fica imperceptível para alguns. O vestir, o andar, o falar e o existir do negro são caracterizados pelos seus fenótipos, estruturalmente os brancos já emitem opiniões sobre os negros e os condicionam a um lugar de inferioridade (ARAÚJO; SOARES, 2019, p. 5).

Tais recriações foram crescentes nos locais de maior concentração de escravizados e seus descendentes, especialmente nas cidades portuárias que mantiveram atividades comerciais com os países da África até as primeiras décadas do século XX. Tendo em vista esse breve histórico da gênese da história, cultura afro-brasileira e o preconceito em torno dessas temáticas, trabalhar e abordar esses conteúdos dentro da sala de aula do Ensino Fundamental do Anos Finais, que é o campo dessa pesquisa, é de profunda importância, pois tende a apreciar os seus valores de vida e do desconhecimento sobre o assunto, combatendo, assim, o aumento da discriminação racial na escola.

A presente pesquisa é documental (fontes primárias - documentos, escritos ou não - ou secundárias - bibliográficas) e descritiva, recorrendo ao método observacional e do tipo exploratória, pois foi sujeita a entrevistas junto aos alunos e professores, adeptos, ou não, do Candomblé. Para a elaboração desse trabalho foram aplicados questionários com professores, gestores, e alunos da Escola Municipal Cordeiro Filho, da cidade da Lagoa dos Gatos, município de Pernambuco. Também foi significativo a visita em terreiros de Candomblé para perceber o envolvimento de crianças e adolescentes na religião e que estejam cursando o Ensino Fundamental do Anos Finais, tendo em vista que alguns alunos são praticantes dessa religião. 
Distribuídos os questionários e realizadas as entrevistas, a intenção foi chegar o mais próximo da realidade e fazer com que o estudo seja útil aos docentes e ao meio acadêmico de uma maneira geral e alinhar junto ao que é proposto pelo livro didático. Destacamos que a identificação das pessoas foi mantida em sigilo, que, nesse caso, foi assinado um acordo entre as partes.

Neste artigo, objetivou-se analisar a partir da visão do conteúdo programático do livro didático, as possibilidades do professor trabalhar a cultura africana e afro-brasileira na sala de aula do Ensino Fundamental dos Anos Finais, reforçando assim a importância da laicidade como instrumento necessário para defender os espaços públicos da intolerância religiosa e analisar a Lei n. 10.639/2003, que versa sobre o ensino da história e da cultura afro-brasileira e africana, enquanto efetivação em sala de aula.

Esperamos que os dados e informações obtidos nesta pesquisa, sejam de grande valia e utilidade para uma profunda reflexão e tomada de atitude, não só pela comunidade escolar, mas também por parte da sociedade com esta temática.

\section{A CONSTRUÇÃO DO CONHECIMENTO HISTÓRICO EM SALA DE AULA}

O ensino de História nas escolas de Ensino Fundamental não se limita a uma mera submissão ao conhecimento produzido pelos historiadores. Nas escolas, alunos e professores geralmente dialogam com os conhecimentos eruditos da História, produzem e (re)produzem conhecimentos históricos. Os professores, então, não são meros reprodutores de conhecimentos produzidos por pensadores que se encontram fora do ambiente escolar. A velha noção de divisão do trabalho entre os que pensam e os que executam o pensado não se enquadra nesse caso.

Os professores, então, cumprem um significativo papel de (re)produzir conhecimentos eruditos importantes para a sociedade, ao mesmo tempo, são pensadores que produzem conhecimentos no espaço escolar. Por isso mesmo, ainda tem sido recorrente a valorização de uma qualificada formação e uma vez bem formados serão para desempenhar as inúmeras tarefas que lhe são atribuídas. Contudo, o ambiente escolar apresenta-se desafiador ao professor para a abrangência de novos conhecimentos face ao que se demanda da própria sociedade representada pelos alunos para ampliação e/ou aquisição de novas aprendizagens. Dito isto e com base no contexto vivenciado pelos 
estudantes, o docente desafia e poder propor novas possibilidades para que se redirecionem, ampliem-se ou desenvolva novos enfoques sobre o conhecimento que é difundido em sala de aula.

Nesse processo, os alunos são envolvidos a buscar, a selecionar informações, a construir hipóteses e a tomar decisões reorganizando e dando sentido e significado ao conhecimento. É importante que sejam incentivados e orientados a refletir criticamente sobre o que lhes é apresentado e a transcender, isto é, ir além das informações obtidas, distinguindo os dados mais importantes dos secundários, buscando relacionar o aprendido com outras informações e situações.

Rüssen (2006) afirma que o aprendizado da História não deve se limitar à aquisição do conhecimento histórico como uma série de fatos objetivos. Para além dessa perspectiva, o conhecimento histórico deve atuar como regra nos arranjos mentais tornando-se, de forma dinâmica, parte integrante da vida do sujeito. Em outras palavras, o conhecimento histórico não significa simplesmente o acúmulo de uma quantidade de informações relacionadas a fatos do passado.

$\mathrm{Na}$ perspectiva da consciência histórica, o conhecimento histórico deve servir como uma ferramenta de orientação temporal que levaria a uma leitura do mundo no presente e embasaria uma avaliação quanto às perspectivas de futuro alicerçadas nas experiências humanas do passado. Desse modo, aqueles que desenvolveram a consciência histórica não conheceriam apenas o passado, mas utilizariam esse conhecimento como meio para auxiliar a compreensão do presente e/ou "antecipar", no plano mental, o futuro em forma de previsão pertinente (MEDEIROS, 2006; BARCA, 2006).

Não obstante as dificuldades do dia a dia nas escolas as narrativas históricas estão presentes por toda a parte e o sujeito historicamente letrado não se limita apenas a somar um novo conhecimento à quantidade de outros tantos que já possui. O letramento em História possibilita ao sujeito estabelecer uma interação mental durante as leituras das narrativas históricas com o conhecimento histórico já acumulado, estabelecendo, assim, uma orientação temporal e permitindo a construção de novos significados. É importante ressaltar que o indivíduo pode utilizar-se de seus conhecimentos históricos para melhor compreender o mundo em que vive e não apenas nas situações em que as narrativas históricas são evidentes. 
É sob essa perspectiva, que nos debruçamos sobre a relevância da abordagem do nosso objeto de estudo. Tendo a consciência de que as religiões afro-brasileiras podem ser discutidas em sala de aula, através e inclusive, a partir das narrativas de alunos e professores, não se atendo apenas ao livro didático. E neste sentido, diagnosticaremos as discriminações históricas a respeito.

Por outro lado, as mudanças exigem novas possibilidades que se tornam inseridas no cotidiano dos estudantes do Ensino Fundamental dos Anos Finais. Neste sentido busca-se na escola o conhecimento sobre as religiões de origem africana por serem questionadas até por professores ao desconhecerem o conhecimento, não somente como responsáveis, por falta mesmo de Formação atualizada. É o que se espera no cotidiano escolar.

\section{METODOLOGIA}

Neste trabalho os livros didáticos escolhidos fazem parte de uma série publicada pela editora FTD e foi adotado numa escola da rede pública. A diversidade cultural pontuada nos livros pode ser percebida a partir de suas capas. Vejamos:

Figura 01: Sequência de imagens de livros didáticos

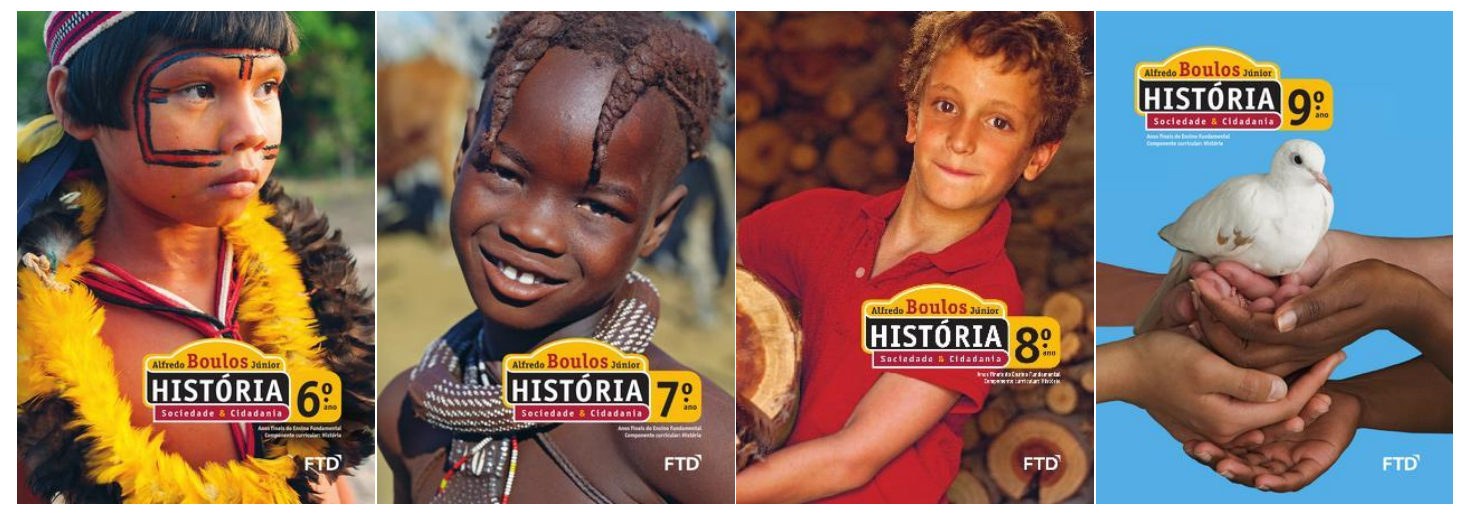

Fonte: Editora Saraiva. (Disponível em: <https://www.saraiva.com.br/historia-sociedadecidadania.html $>$ ). Acesso em junho de 2020.

Nas observações da professora que trabalha em escola pública no município da Lagoa dos Gatos, alunos do $6^{\circ}$ ao $9^{\circ}$ ano, as capas dos livros causaram grande impacto às crianças, principalmente do livro do $7^{\circ}$ ano que traz a imagem de uma criança africana. Foi necessário abordar em sala de aula a cultura diferente de alguns países e a forma como 
as pessoas se vestem, se cuidam e se embelezam. Dentre as capas, a mais criticada e observada pelos alunos foi esta. Frases como: "Que criança feia" ou "Parece que passou cocô no cabelo" foram ditas. Ao longo do ano, a professora aproveitou alguns momentos para elogiar, "despretensiosamente", a criança da capa, na tentativa da mudança de olhar diferente o belo. Sobre essa questão do belo, também foi trabalhado em outra disciplina, a de Língua Portuguesa, para desmitificar o padrão de beleza que as crianças acreditam que exista. A imagem da capa do $9^{\circ}$ ano, última série do Fundamental Anos Finais, já leva aos alunos a perceberem a união entre nossas diferenças, exemplificando a necessidade da paz entre nós, com a simbologia de uma pomba branca. Passemos ao conteúdo das obras: no livro do $6^{\circ}$ ano são abordados os seguintes temas sobre África e cultura afro-brasileira:

- A valorização das matrizes africana e indígena (uma página com imagens citando o Tambor de Crioula do Maranhão);

- Patrimônio cultural (uma página com atividade sobre a capoeira);

- Patrimônio cultural (uma página com atividade sobre o frevo, enfatizando a origem da dança na capoeira);

- Os primeiros hominídeos (uma página a qual faz referência à origem da humanidade no continente africano);

- Da África para outros continentes (quatro páginas que abordam a origem do homem e como ocorreu a povoação dos continentes com suas hipóteses de rota a partir da África);

- O Egito Antigo e o Reino de Kush (um capítulo abordando esses dois impérios, contendo duas páginas e meia falando sobre a religiosidade egípcia);

Percebe-se, portanto, que o livro do $6^{\circ}$ ano aborda muito superficialmente sobre a influência da cultura afro-brasileira, apenas quando se trata de patrimônio cultural, mas em nenhum momento fala-se sobre religiosidade afro-brasileira. Apesar de abordar a mitologia egípcia, essa não faz parte de nossas influências. Aqui, neste espaço, cabe ao professor ou professora, abrir espaço para o debate sobre a mitologia dos orixás, para que os estudantes entendam que existem várias mitologias, a exemplo da egípcia, grega, germana e iorubá.

No livro do $7^{\circ}$ ano analisado, temos:

- A unidade 1 inicia com o tema diversidade e discriminação religiosa, no entanto, dá ênfase à tríade islamismo-judaísmo-cristianismo. A ideia é introduzir o conteúdo da Europa Medieval a partir do entendimento da intolerância religiosa, visto que o 
capítulo se encerra com o tema das cruzadas, guerra religiosa a qual envolvia essas três religiões.

No entanto, nesse início de unidade, a professora pode discutir sobre o atual contexto que vivemos no Brasil, onde as religiões de matriz africana são duramente perseguidas por religiões cristãs.

- Povos e culturas africanas: malineses, bantos e iorubas (um capítulo que aborda esses reinos africanos e as influências culturais que eles trouxeram para o Brasil).

Apesar de toda a influência religiosa que esses povos nos trouxeram, a narrativa do livro perde a oportunidade de aprofundar o assunto sobre as religiões de matrizes africanas e ne se quer fala sobre Candomblé, por exemplo. Porém, o debate pode ser sugerido em sala para que possam ser abordados o Candomblé e Umbanda, Jurema, por exemplo. Na ocasião pode ser feita uma investigação para descobrir se existem adeptos dessas religiões em sala de aula.

- A economia açucareira (seis páginas abordando sobre a mão de obra escrava no Brasil colonial);

Esse tema já é muito usual nos livros didáticos de uma maneira geral. A novidade seria aprofundar o conteúdo fazendo uma relação da mão de obra nos tempos do Brasil Colonial com os dias atuais. Pode-se trabalhar, neste caso, o mercado de trabalho para negros e negras do Brasil, o índice de escolaridade, de presidiários e a situação atual do negro no Brasil. Neste capítulo não há nenhuma menção sobre a dimensão religiosa afrobrasileiras e suas dificuldades ao serem trabalhadas nas escolas. Há um silêncio nesse aspecto. Também seria uma oportunidade de estudar sobre este tema.

O livro do $8^{\circ}$ ano aborda as seguintes questões relacionadas aos negros e à África:

- Africanos no Brasil: dominação e resistência (um capítulo que trata da escravidão, do tráfico de escravizados, do trabalho, da violência, da resistência e dos quilombos).

O momento em que se fala em resistência poderia ser abordado sobre a resistência religiosa, que apesar de proibições e perseguições, as religiões de matriz africana resistem até os dias atuais. Como o livro deixa a desejar neste sentido, a professora pode levantar o debate em sala de aula. 
- A sociedade mineradora (uma página que aborda os escravizados da região das minas).

Nesse trecho de capítulo, pouco se fala sobre a religião, as festas e a resistência. Apenas uma breve menção sobre a congada.

- Conjuração Baiana (duas páginas que abordam brevemente sobre a presença da população afrodescendente em Salvador).

- Revolta dos Malês (duas páginas que tratam da revolta escrava considerada a mais importante do Brasil). A seção esclarece o motivo pelo qual a revolta fica conhecida como Revolta dos Malês e traz algumas imagens de africanos e afro-brasileiros.

- A pressão inglesa e o fim do tráfico (três páginas abordando o tráfico de escravizados e a pressão que os ingleses passam a fazer à coroa portuguesa para que o mesmo fosse extinto).

- A abolição (oito páginas que fazem um percurso histórico sobre o movimento abolicionista, as leis que foram instituídas e a realidade que acontecia à época).

Por fim, no livro do $9^{\circ}$ ano, os conteúdos abordados sobre nosso objeto de estudo são:

- Teorias racistas do século XX (uma página com atividade de interpretação de texto).

- O imperialismo na África (três páginas que tratam da exploração sofrida em regiões do continente africano. Esse trecho também aborda brevemente a resistência dos africanos através de rebeliões. As questões trabalhadas são mais políticas).

- A Revolta da Chibata (uma página e meia que trata desse episódio de resistência, face à permanência de condutas escravagistas. Aqui não há espaço para falar-se em questões religiosas).

- O nazismo na Alemanha (seis páginas que abordam esse momento histórico. Inserido nesse contexto, brevemente a seção trata da superioridade da raça ariana).

- Independências: África e Ásia (um capítulo sobre o tema, sendo que sobre África são seis páginas com atividades). Nesta seção, os aspectos trabalhados são o econômico e político, sem espaço para as questões religiosas.

Observamos que em todos os livros da série, os aspectos religiosos são deixados de lado. Quando abordados, são abordados muito superficialmente. Das possíveis oportunidades, dentro do conteúdo, o professor ou a professora deve levantar debates, fazer pesquisas, expor o tema, independentemente do livro.

\section{RESULTADOS E DISCUSSÃO}

Por seu lado o estudo das religiões afro-brasileiras há muito se rejeitava de modo que se expandiram nos processos de discriminação e associação a uma cultura inferior, 
quando não ao próprio mal, ao demônio, de modo que não conhece sobre tais religiões que em sua matriz africana não se identifica essa representação.

Já nas primeiras pesquisas sobre a cultura afro-brasileira, ou sobre o negro no Brasil, realizadas por Nina Rodrigues (2010) e Arthur Ramos (2001), ambos médicos, mas que se empenharam em investigar as raízes do povo negro no Brasil, percebe-se o tom pejorativo ou negativo dado à cultura dos africanos. Exemplo disso é quando Nina Rodrigues (2010, p. 242) refere-se a Olorum, criador do mundo, conforme a mitologia dos Orixás, como uma "concepção da minoria inteligente". Ao mesmo tempo em que os autores se referem a fé africana como fetichismo. Em nota, Lima (2016, p. 80) atribui que:

O termo é utilizado tanto na obra de Arthur Ramos quanto na de Nina Rodrigues. Origina da palavra feitiço, o que nos remete a utilização do termo na Idade Média, que estava ligada à bruxaria, que se relaciona mais com o demônio que com a fé, dando a entender que as tradições religiosas de origem africana estão relacionadas ao mal. Na África, a conotação da palavra está relacionada aos deuses particulares.

Neste sentido Nina Rodrigues e Arthur Ramos, irão embasar com as suas ideias um discurso preconceituoso e discriminatório, que reflete a sociedade do final do século XIX e início do século XX, mas que perpassam até nossos dias.

Mesmo com uma mudança no contexto referencial histórico de autores mais contemporâneos que tratam sobre as raízes africanas nos brasileiros a exemplo de Roger Bastide (1971; 2001), José Beniste (2014) e Reginaldo Prandi (2001), os quais dão ênfase à mitologia dos orixás, a explicarem sobre este panteão, e outros tantos que debatem sobre racismo, como o clássico Oracy Nogueira (1954-1985), vivenciamos em pequenos ou grandes espaços, as práticas de intolerância religiosa e os discursos de ódio das mais diferentes maneiras. Assim busca-se que o livro didático venha contribuir com a formação dos estudantes, mediados pelo professor ou professora.

Assim visto nas pesquisas há algumas décadas o livro didático não é um instrumento moderno, estudos comprovam que, na metade do século XVI, já existia uma preocupação em adotar livros adequados para a prática de transmissão de conhecimentos. No Brasil, o livro didático é controlado pelo Estado através da legislação desde 1938, pelo Decreto n. 8.469.

Não obstante os livros tem mudado no século atual, assim estes instrumentos didáticos só podem ser adotados com a autorização do Ministério da Educação. Ou seja, 
o livro deve cumprir o papel de estimulador da cidadania, produzindo efeito contrário a todo e qualquer tipo de preconceito e discriminação dentro ou fora da escola como se tem registro de imagens de livros didáticos dos anos 1940 (BITTENCOURT, 1993) onde o indígena era visto como passivo e inferior. Por sua vez os negros eram apresentados sempre em trabalhos "pesados" no campo, disseminados a indicar dificuldades na aprendizagem, quando as pesquisas dos anos 1940 e 1950 já mostravam visões, se bem que isoladas ideologicamente, de grandes destaques na sociedade brasileira quer seja na arte, no teatro, nas grandes obras, na literatura, e outros campos (NASCIMENTO, 2017).

Isto quer dizer que, está presente na maioria dos livros didáticos, formas de discriminação ao negro, além da presença de estereótipos, que equivalem a uma espécie de rótulo utilizado para qualificar de maneira conveniente grupos étnicos, raciais ou, até mesmo, sexos diferentes, estimulando preconceitos, produzindo assim influências negativas, baixa autoestima às pessoas pertencentes ao grupo do qual foram associadas tais "características distorcidas". Por ser o principal portador de conhecimentos básicos das variadas disciplinas que compõem o currículo dentro das escolas, o livro didático torna-se um dos recursos mais usados em sala de aula, e um instrumento pedagógico bastante difundido, por isso facilita à ação da classe dominante de registrar como quer e como lhe convém a imagem do negro na sociedade brasileira.

Caberá ao professor ter a preocupação com a forma pela qual o conteúdo histórico é exposto nos livros didáticos, na medida em que possam contribuir para combater as abordagens incompletas e estereotipadas das imagens dos afrodescendentes. A Lei n. 10.639/2003 versa sobre a inserção do estudo da História da África e cultura afrobrasileira e as resistências que percebemos em nossa prática, na abordagem sobre o que se refere ao continente. Ora por estranheza, desconhecimento e discriminação, em sala de aula observa-se uma recusa constante, uma negação por este conteúdo e esse diagnóstico é visível, vindo de professores ou estudantes. Dispõe a lei 10.639/2003 em seu artigo $3^{\circ}$ :

Art. $3^{\circ}$ A Educação das Relações Étnico-Raciais e o estudo de História e Cultura Afro-Brasileira, e História e Cultura Africana será desenvolvida por meio de conteúdos, competências, atitudes e valores, a serem estabelecidos pelas Instituições de ensino e seus professores, com o apoio e supervisão dos sistemas de ensino, entidades mantenedoras e coordenações pedagógicas, atendidas as indicações, recomendações e diretrizes explicitadas no Parecer CNE/CP 003/2004 (DCN, 2004, p. 32). 
O conteúdo exige que o professor tenha conhecimento e formação específica, o que ainda não observamos na prática essa realidade. Na prática, a discriminação racial é retratada nos conteúdos que são abordados nos livros didáticos, a exemplo do que apresentamos com a série História: sociedade \& cidadania. A série se atém ao passado escravocrata e apenas aborda muito brevemente alguns aspectos e heranças da cultura afro-brasileira. Neste contexto, questões religiosas são deixadas de lado e o candomblé, sequer é mencionado nos livros.

Em geral, em nossas escolas os conteúdos de história brasileira contam apenas uma versão dos fatos históricos, pautada numa visão eurocentrista da descoberta de nosso país e do desenrolar da economia daquela época, apresentando a história do negro apenas por meio do negro escravo, do tráfico negreiro, um pouco das senzalas e muito pouco ou quase nada do modo de vida e da ascendência africana (COUTINHO et al, 2008, p. 76).

É preciso entender que a história dos afrodescendentes vai além de um passado escravocrata. É preciso que se apresente em temas e textos, o protagonismo, valorizando aspectos históricos, culturais, religiosos, econômicos, sociais, intelectuais. E isso ainda está muito aquém do ideal.

Primeiramente, é necessário que os profissionais da educação superem o racismo e o preconceito para abordarem o tema da religiosidade afro-brasileira, visto que ainda se percebe no dia a dia a permanência de discursos discriminatórios que foram perpassados ao longo de nossa história cristã. Essa característica faz com que muitos da área da educação ainda considerem a religião africana uma prática demoníaca e profana, desconsiderando o seu verdadeiro valor de relações de permanências, resistências, mudanças, históricas. A implementação da lei teve seu fator positivo, pois despertou em nós a importância de se levar para sala de aula conteúdos não abordados. Também detectou a dificuldade dos professores para abordar o tema e a necessidade de investimentos na formação desses profissionais.

\section{CONSIDERAÇÕES FINAIS}

As religiões de matriz africana foram incorporadas à cultura brasileira desde há muito, quando os primeiros escravizados desembarcaram no país e encontraram em sua religiosidade uma forma de preservar suas tradições, idiomas, conhecimentos e valores 
trazidos da África. E assim como tudo que fazia parte deste universo, tais religiões, apesar de sua influência e importância na construção da cultura nacional, também foram perseguidas e, em determinados momentos históricos, até proibidas. Atualmente, os ataques mais expressivos às religiões de matriz africana vêm das chamadas religiões "neopentecostais", que comumente as rotulam de "culto aos demônios", "crendices" e "feitiçarias".

Paralelo a esse debate, também analisamos a lei n. 10.639/2003, que versa sobre a inserção do estudo da História da África e Cultura Afro-brasileira e as resistências que foram percebidas em nossa prática, na abordagem sobre o que se refere ao continente. Ora por estranheza, desconhecimento e discriminação, em sala de aula observou-se uma recusa constante, uma negação por esse conteúdo e esse diagnóstico foi visível, vindo muito mais dos professores do que os estudantes.

Toda essa ignorância com relação a essas culturas gera um ambiente propício para intolerância, proporcionando sofrimento aos praticantes e a todos aqueles/as que fazem parte da população negra, que tem o seu direito de pertença e identidade racial muitas vezes negado em função do racismo.

As representações construídas sobre o negro e sua cultura, no interior do ambiente escolar, tanto pode valorizar identidades, diferenças e o respeito à diversidade racial, quanto pode estigmatizá-las, discriminá-las, segregá-las e até mesmo negálas. A construção de uma identidade negra positiva representa um desafio, principalmente, convivendo e vivendo num imaginário pedagógico que olha e trata os negros e sua cultura de maneira desigual e institucionalizada, pelo menos até antes da Lei $\mathrm{N}^{\circ} 10.639 / 03$, e mesmo diante dos avanços que decorrem de tal legislação, as dificuldades ainda se demonstram no cotidiano escolar (COELHO; BERNARDO DIAS, 2020, p. 55).

Espera-se que a leitura deste artigo seja útil e ajudado os leitores a perceber a mistura de etnias existente no Brasil e que a maioria das crenças são frutos dessa mistura. Que possam reconhecer e valorizar a diversidade humana, partindo de um processo de conhecimento e respeito de nossas identidades culturais, com o intuito de resgatar e fomentar atitudes individuais e coletivas contra o preconceito e a favor do respeito às diferenças.

\section{REFERÊNCIAS BIBLIOGRÁFICAS}


ARAÚJO, Aldevane de Almeida; SOARES, Emanoel Luis Roque. Identidade e relações étnicoraciais na formação escolar. Rev. Pemo, Fortaleza, v. 1, n. 1, p. 1-14, 2019. Disponível em: https://revistas.uece.br/index.php/revpemo/article/view/3628. Acesso em: 15 de set. de 2020.

BARCA, Isabel. Literacia e consciência histórica. Educar, Especial, p. 93-112. Editora UFPR. Curitiba, 2006.

BASTIDE, Roger. As religiões africanas no Brasil: contribuição a uma sociologia das interpretações de civilizações. São Paulo: Pioneira, 1971. (Biblioteca Pioneira de Ciências Sociais).

. O candomblé da Bahia. 3. ed. São Paulo: Companhia das Letras, 2001.

BENISTE, José. Òrun Àiyé: o encontro de dois mundos: o sistema de relacionamento nagôyorubá entre o céu e a Terra. 11. ed. Rio de Janeiro: Bertrand Brasil, 2014.

BITTENCOURT, Circe Fernandes. Livro didático e conhecimento histórico: uma história do saber escolar. Tese de doutorado em História Social, Departamento de História da Faculdade de Filosofia, Ciências e Letras da Universidade de São Paulo, 1993.

BRASIL. Ministério da Educação. Diretrizes Curriculares Nacionais para a Educação das Relações Étnico-Raciais e para o Ensino de História e Cultura Afro-Brasileira e Africana. Brasília: $M E C / S E F, 2004$.

CARDOSO, Odimar. Para uma definição de didática da história. Revista Brasileira de História. v. 28, n 55, p. 153-170. São Paulo, 2008.

COELHO, Wilma de Nazaré Baía; BERNARDO DIAS, Sinara. RELAÇÕES RACIAIS NA ESCOLA: ENTRE LEGISLAÇÕES E COORDENAÇÕES PEDAGÓGICAS. Revista da Associação Brasileira de Pesquisadores/as Negros/as (ABPN), [S.1.], v. 12, n. 32, p. 46-67, maio 2020. Disponível em: Disponível em: <https://abpnrevista.org.br/index.php/site/article/view/883>. Acesso em: 18 out. 2020.

COUTINHO, Ana Cecília Porto Cunha et al. Raça, etnia e a escola: possibilidades de Implementação da Lei 10.639/03. Cadernos de Pedagogia, ano 2, v. 2, n. 4, ago.-dez./2008, p. 74-85.

DEL PRIORE, Mary; VENÂNCIO, Renato Pinto. Ancestrais: uma introdução à história da África Atlântica. Rio de Janeiro: Elsevier, 2004.

DUARTE, Newton. A escola de Vigostsky e a educação escolar: algumas hipóteses para uma leitura pedagógica da psicologia histórico-cultural. Revista de Psicologia. v.7, n. 12, p. 17-50. USP: São Paulo, 1996.

FERNANDES, Florestan. O negro no mundo dos brancos. São Paulo: Global, 2007.

FERRO, Marc. A colonização explicada a todos. São Paulo: Editora Unesp, 2004.

FREYRE, Gilberto. Casa grande \& senzala: formação da família brasileira sob o regime da economia patriarcal. São Paulo: Global, 2006a. 
Sobrados e mucambos: decadência do patriarcado e desenvolvimento urbano. São Paulo:

Global, 2006b.

LIMA, Adriana Luzia. Filhos-de-santo, história e candomblé: narrativa e experiência do Xangô em Alagoas. Dissertação (mestrado em História). Maceió, Universidade Federal de Alagoas, 2016.

MEDEIROS, Daniel Hortêncio de. Manuais didáticos e a formação da consciência histórica. Educar, Especial, p. 73-92. Editora UFPR. Curitiba, 2006.

NASCIMENTO, Abdias. O genocídio do negro brasileiro: processo de um racismo mascarado. São Paulo: perspectiva, 2017.

NOGUEIRA, Oracy. Preconceito racial de marca e preconceito racial de origem. In: Tanto preto quanto branco: estudos de relações raciais. São Paulo, T.A. Queiroz, 1954-1985.

PRANDI, Reginaldo. Mitologia dos orixás. São Paulo: Companhia das letras, 2001a. 590p.

RÜSSEN, Jörn. Didática da história: passado, presente e perspectiva a partir do caso alemão. Práxis Educativa. v. 1, n. 2, p. 7-16, Ponta Grossa, PR. jul.-dez. 2006.

SILVA, Ana Célia. A discriminação do negro no livro didático. Salvador: CED - Centro Editorial Didático e CEAO - Centro de Estudos Afro - Orientais, 1995, p 34; 47; 135.

SILVA, Marcos Antônio; FONSECA, Selva Guimarães. Ensino de História hoje: errâncias, conquistas e perdas. Revista Brasileira de História, v.30. n.60. dez. 2010.

SOARES, Magda. Letramento: um tema em três gêneros. 2. ed. Belo Horizonte: Autêntica, 2005.

Recebido em: 23/11/2020

Aprovado em: 18/10/2021 